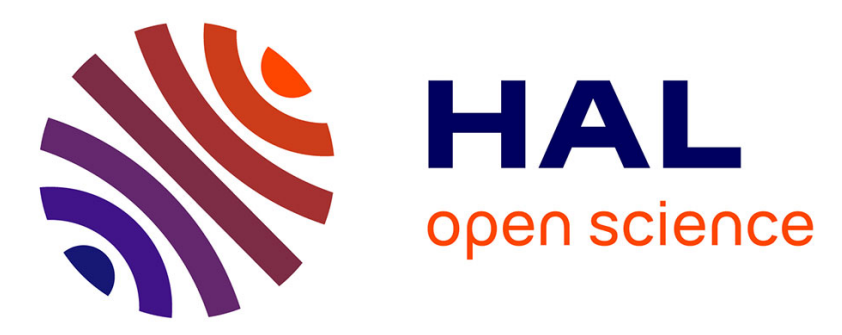

\title{
Efficacy of the combination of bortezomib and dexamethasone in systemic AL amyloidosis
}

W. Lamm, W. Willenbacher, A. Lang, N. Zojer, E. Müldür, H. Ludwig, B. Schauer-Stalzer, C. C. Zielinski, J. Drach

\section{- To cite this version:}

W. Lamm, W. Willenbacher, A. Lang, N. Zojer, E. Müldür, et al.. Efficacy of the combination of bortezomib and dexamethasone in systemic AL amyloidosis. Annals of Hematology, 2010, 90 (2), pp.201-206. 10.1007/s00277-010-1062-6 . hal-00574000

\section{HAL Id: hal-00574000 \\ https://hal.science/hal-00574000}

Submitted on 7 Mar 2011

HAL is a multi-disciplinary open access archive for the deposit and dissemination of scientific research documents, whether they are published or not. The documents may come from teaching and research institutions in France or abroad, or from public or private research centers.
L'archive ouverte pluridisciplinaire HAL, est destinée au dépôt et à la diffusion de documents scientifiques de niveau recherche, publiés ou non, émanant des établissements d'enseignement et de recherche français ou étrangers, des laboratoires publics ou privés. 
Efficacy of the combination of bortezomib and dexamethasone in systemic AL amyloidosis

Lamm $W^{1}$, Willenbacher $W^{2}$, Lang $A^{4}$, Zojer $\mathrm{N}^{3}$, Müldür $\mathrm{E}^{3}$, Ludwig $\mathrm{H}^{3}$, Schauer-Stalzer $\mathrm{B}^{1}$, Zielinski $\mathrm{CC}^{1}$ and Drach $\mathrm{J}^{1}$

${ }^{1}$ Department of Medicine I, Clinical Division of Oncology, Medical University of Vienna, Austria;

${ }^{2}$ Departement of Hematology and Oncology, University Hospital Innsbruck, Innsbruck,

Austria;

${ }^{3}$ Departement of Medicine I, Wilhelminenspital Vienna, Vienna, Austria

${ }^{4}$ Departement of Internal Medicine, Division of Oncology, Landeskrankenhaus Feldkirch, Feldkirch, Austria

Corresponding author:

Johannes Drach, MD

Medical University of Vienna

Department of Medicine I

Clinical Division of Oncology

Waehringer Guertel 18-20

A-1090 Vienna, Austria

Phone: +43140400 4429

Fax: +431404004451

e-mail: johannes.drach@meduniwien.ac.at 


\begin{abstract}
Bortezomib - Dexamethasone (Btz/Dex) is an active regimen in patients with multiple myeloma and has been used in few patients with amyloidosis. Here we report a retrospective evaluation of the efficacy and toxicity of Btz/Dex in 26 patients with AL amyloidosis. 18 patients (69\%) received Btz/Dex as first-line treatment. Organs most frequently involved were kidneys $(100 \%)$ and heart $(35 \%), 5$ patients $(19 \%)$ had $>2$ organs involved. The overall response rate was 54\% (14 of 26 patients), with 8 patients (31\%) achieving a hematologic complete remission (CR). All patients who reached a CR received Btz/Dex as first-line therapy. Median time to response was 7.5 weeks. Improvement in organ function was noticed in 3 patients (12\%). Median progression free survival (PFS) and overall survival (OS) was 5.0 and 18.7 months, respectively; in CR patients, however, median PFS and OS have not yet been reached. Toxicities were manageable, with haematological side effects being most common. No grade 3/4 neuropathy was observed. Our results confirm the activity of bortezomib/dexamethasone in patients with $\mathrm{AL}$ amyloidosis and suggest that patients achieving a CR have a marked benefit for survival.
\end{abstract}

\title{
Keywords:
}

AL amyloidosis, bortezomib, proteasome inhibition, complete remission 


\section{Introduction}

Primary systemic AL-amyloidosis (AL) is a clonal plasma cell disorder characterized by the deposition of amyloid fibrils in various organs, which eventually leads to organ dysfunction and death [1]. Prognosis of AL is poor, with a median survival of about a year from diagnosis without treatment, but survival may be prolonged by effective treatment [2]. The pathogenic light-chains are produced by a usually relatively small clonal population of immunoglobulinsecreting, transformed plasma cells. Therefore, the objective of treatment in AL is suppression of the abnormal plasma cell clone, which then leads to a reduction of amyloidogenic light chains. Treatment choices depend on the patient's age, performance status and the type of organ damage [3].

Aggressive therapy consisting of high-dose melphalan followed by autologous stem cell transplantation has been shown to be effective in AL [4], but only a minority of patients is eligible for this treatment modality [5]. Less intensive treatment approaches include an alkylating agent (usually melphalan) in combination with a corticosteroid [6]. Melphalan plus dexamethasone (Dex) can induce a hematologic response in up to $67 \%$ of patients with $\mathrm{AL}$; however, median time to response is rather long (4.5 months). Thalidomide combined with Dex appears to be only moderately active in AL (hematologic response rate of less than 50\%), but of even greater concern is the considerable toxicity of this regimen in patients with AL [7]. Therefore, effective treatment strategies are still urgently required for patients with AL, both in newly diagnosed and relapsed disease.

Novel agents with proven activity in multiple myeloma (MM) are investigated in AL. Initial experiences with lenalidomide in AL have been promising, but more data are needed to establish its therapeutic role in this plasma cell disorder [8-11].

Bortezomib (Btz) is a potent, specific and reversible inhibitor of the $26 \mathrm{~S}$ proteasome with remarkable activity in multiple myeloma (MM) [12]. Based upon the sensitivity of malignant plasma cells to Btz and the usually rapid onset of a remission induced by Btz, it has been hypothesized that proteasome inhibition should also be beneficial in AL. Two reports with single-agent Btz have shown promising activity and manageable toxicity in patients with relapsed AL [8,9]. In MM, the efficacy of Btz can be enhanced by the addition of Dex, which may also be true in AL. We therefore evaluated the efficacy and toxicity of the combination of Btz and Dex in a series of consecutive patients with AL. 


\section{Materials and methods}

\section{Patients' characteristics}

This multicenter retrospective analysis outside the context of a clinical trial was performed on a consecutive cohort of 26 patients $($ male $=13$, female $=13$ ) with biopsy-proven, symptomatic AL amyloidosis. Diagnosis of AL and assessment of amyloid related organ involvement followed recently published consensus guidelines [13]. Baseline characteristics including organ involvement are detailed in Table 1. Median age was 62 years (range 42-83). Treatment with Btz/Dex was performed between October 2006 and October 2009. Eighteen patients received Btz/Dex as first-line treatment, whereas 8 patients were treated at relapse. In patients with previously treated AL, the median number of prior treatment lines was 2 (range, 1 to 6). The most common prior treatment regimens consisted of melphalan/prednisone (already administered in 50\% of pretreated patients), vincristine/adriamycin/dex (VAD; 25\%) and DCEP (25\%). In 23 of the patients, ECOG performance status was $\leq 2,3$ patients had an ECOG performance status $>3$.

\section{Treatment regimen}

Btz was administered at a standard dose $1.3 \mathrm{mg} / \mathrm{m}^{2}$ as an intravenous bolus twice weekly for two weeks (days 1, 4, 8 and 11) followed by a 10-day rest period (days 12-21). Dex was administered at a daily dose of $20 \mathrm{mg}$ on the days of Btz administration and the day after. Cycles were repeated every 3 weeks. Patients could receive up to 8 cycles of therapy. All patients received antiviral prophylaxis and proton-pump inhibitor therapy according to the standards of individual institutions. Since this was not a prospective trial, dose modifications of Btz and Dex were performed in agreement with guidelines from standard MM treatment at the discretion of the individual physician. Supportive therapy for side effect management was administered according to clinical requirements.

Patients were informed that treatment with Btz had been demonstrated to be active in MM, and that it was licensed for the treatment of patients with MM, but that experience with Btz in AL was limited thus far. All patients gave written informed consent to treatment.

\section{Assessments}

Physical examination, standard laboratory parameters, serum electrophoresis and serum free light chains were obtained on a monthly basis. Performance status was assessed as described by the Eastern Cooperative Oncology Group (ECOG) criteria. Toxicity was recorded 
according to the National Cancer Instiute Cancer Therapy Evaluation Program, Common Terminology Criteria for Adverse Events (Version 3.0).

Patients were considered to be evaluable for outcome after completion of at least two cycles of Btz/Dex. Response to therapy was defined according to recently published consensus guidelines [13]. Partial response (PR) was defined as a $>50 \%$ decrease of the involved monoclonal class; complete remission (CR) was defined as a normalization of the serum free light chain (kappa/lambda) ratio and both light chain classes. Organ response (OR) was only assessed in patients who responded to Btz.

Statistical analyses

Progression free survival (PFS) was calculated from the date of Btz/Dex initiation until the date of progression or death. Overall survival (OS) was calculated from the time of initiation of therapy and death from any cause or last follow-up. Survival curves were plotted using the Kaplan-Meier method, and survival curves were compared by the log-rank test. 


\section{Results}

Response

Treatment outcome of Btz/Dex in 26 patients with AL is summarized in Table 2. The overall response rate was $54 \%$ (14 of 26 patients), with 8 patients achieving a hematologic CR (31\%) and 6 additional patients achieving a PR (23\%). Of note, only one patient experienced a disease progression. Similar overall response rates were observed among untreated patients (58\%, 10 of 18 patients) and previously treated patients (50\%, 4 of 8 patients); however, all patients who reached a CR received Btz/Dex as first-line therapy. Median time to response was 7.5 weeks.

Improvement in organ function was noticed in 3 patients (12\%); in 20 patients (76\%), organ function remained stable, whereas progressive organ failure was noted in 3 patients (12\%).

Survival

Median follow-up of surviving patients was 14.6 months. Median PFS and OS were 5.0 months and 18.7 months, respectively (Table 2, Figure 1-4). When survival times were analyzed according to the quality of response, it became evident that patients achieving a hematologic CR had longer PFS and OS (medians not yet reached) compared to AL patients who did not achieve a CR (median PFS, 2.6 month; median OS 8.9 months).

\section{Toxicity}

A summary of observed side effects is given in Table 3 . The most common grade $3 / 4$ toxicities were thrombocytopenia and hyponatremia. Grade 2 neurotoxicity was observed in $42 \%$ of patients. Other grade 1 and 2 toxicities observed at high frequencies included edema (27\%), hypotension (23\%) and fatigue (23\%). Two patients with previously treated AL experienced cardiac side effects (arrhythmias) judged to be related to Btz. 


\section{Discussion}

The aim of this retrospective multicenter study was to evaluate the effect of Btz/Dex in patients with AL amyloidosis. The documented activity of Btz/Dex in MM and the recently developed hypothesis that amyloidogenic plasma cells may be particularly sensitive to proteasome inhibition [14] provide the background for exploring Btz in patients with AL. Plasma cells in AL tend to accumulate unfolded toxic light chains, which could further increase the endoplasmic reticulum stress [15] eventually leading to apoptosis. Inhibition of the proteasome by Btz exaggerates endoplasmic reticulum stress, further stabilizes proapoptotic factors and thereby enhances induction of apoptosis [14]. Response rates to Btzbased regimens in the order of $50-94 \%$ including a hematologic CR rate of $15 \%$ to $43 \%$ are in support of this hypothesis [8,9]. In agreement with these reports, our results with Btz/Dex show a $54 \%$ overall response rate, with $31 \%$ of patients achieving a CR. Furthermore, the short time to the onset of a remission (median, 7.5 weeks) is an important feature of Btz/Dex treatment for AL. This is markedly different from what has been reported with other regimens, e.g. melphalan plus Dex and thalidomide plus Dex (median time to response, 4.5 months and 3.6 months, respectively) [6,7]. With the known limitations of a retrospective analysis, these results reflect a real-life scenario of AL patients because data were derived from a consecutive series of $\mathrm{AL}$ patients treated quite uniformly at major hematology/oncology centres.

A particular finding in our patient series was the association of a hematologic CR with prolonged PFS and OS (Figures 2 and 4). Response to treatment was linked to survival of patients with $\mathrm{AL}$ in previous studies employing high-dose melphalan and autologous transplantation [4]. This observation can now be extended to the setting of Btz-based therapy in AL. Overall, the importance of achieving a good quality remission is reminiscent of what has been described in MM, where depth of remission is associated with improved outcome $[16,17]$.

Kastritis et al. reported for the first time the efficacy of the proteasome inhibitor Btz in patients with AL amyloidosis. The hematologic response rate was observed in 94\%, including a 44\% CR. The median follow up was 11.2 months [8]. Wechalekar et al. conducted a trial in which heavily pretreated patients received Btz with or without Dex. Btz was median the third line therapy (range $1-6)$. Seven out of $9(77 \%)$ patients who were given the combination of Btz/Dex responded. The median survival was not reached at 24 months from the end of treatment [9]. Due to the multisystemic organ involvement toxicity is a major problem in 
these patients. Different therapies, e.g. thalidomide or lenalidomide, were not tolerated in patients with AL amyloidosis [7,10,5]. In our patient series, toxicity of Btz/Dex treatment was limited and adverse events were manageable with routine clinical care. Most grades $3+4$ toxicities consisted of thrombocytopenia and hyponatriemia (4\%), respectively, and appeared to be lower than in other studies. Pretreated patients with cardiac involvement should be monitored closely because of their high risk of cardiac complications [8,18].

In conclusion, our results confirm the activity of the combination of bortezomib and dexamethasone in elderly untreated und treated patients with AL amyloidosis. Adverse events are rare and manageable. Patients achieving a hematologic CR derive the greatest benefit from treatment with Btz/Dex which suggests that therapeutic strategies enhancing the CR-rate in $\mathrm{AL}$ are warranted for future investigations. 


\section{References}

1. Merlini G, Bellotti V (2003) Molecular mechanisms of amyloidosis. N Engl J Med 349: 583-596.

2. Kyle RA, Gertz MA, Greipp PR, Witzig TE, Lust JA, Lacy MQ, Therneau TM (1997) A trial of three regimens for primary amyloidosis: colchicine alone, melphalan and prednisone, and melphalan, prednisone and colchicine. N Engl J Med 336: 1202-1207.

3. Merlini G, Stone MJ (2006) Dangerous small B-cell clones. Blood 108: 2520-2530.

4. Comenzo RL, Gertz MA (2002) Autologous stem cell transplantation for primary systemic amyloidosis. Blood 99: 4276-4282.

5. Sanchorawala V, Wright DG, Seldin DC, Dember LM, Finn K, Falk RH, Berk J, Quillen K, Skinner M (2001) An overview of the use of high-dose melphalan with autologous stem cell transplantation for the treatment of AL amyloidosis. Bone Marrow Transplant 28: 637-642.

6. Jaccard A, Moreau P, Leblond V, Leleu X, Benboubker L, Hermine O, Recher C, Asli B, Lioure B, Royer B, Jardin F, Bridoux F, Grosbois B, Jaubert J, Piette JC, Ronco P, Quet F, Cogne M, Fermand JP; Myélome Autogreffe (MAG) and Intergroupe Francophone du Myélome (IFM) Intergroup. (2007) High-dose melphalan versus melphalan plus dexamethasone for AL amyloidosis. N Engl J Med 357: 1083-1093.

7. Palladini G, Perfetti V, Perlini S, Obici L, Lavatelli F, Caccialanza R, Invernizzi R, Comotti B, Merlini G (2005) The combination of thalidomide and intermediate-dose dexamethasone is an effective but toxic treatment for patients with primary amyloidosis (AL). Blood 105: 2949-2951.

8. Kastritis E, Anagnostopoulos A, Roussou M, Toumanidis S, Pamboukas C, Migkou M, Tassidou A, Xilouri I, Delibasi S, Psimenou E, Mellou S, Terpos E, Nanas J, Dimopoulos MA (2007) Treatment of light chain (AL) amyloidosis with the combination of bortezomib and dexamethasone. Haematologica 92: 1351-1358. 
9. Wechalekar AD, Lachmann HJ, Offer M, Hawkins PN, Gillmor JD (2008) Efficacy of bortezomib in systemic AL amyloidosis with relapsed/refractory clonal disease. Haematologica 93: 295-298.

10. Dispenzieri A, Lacy MQ, Zeldenrust SR, Hayman SR, Kumar SK, Geyer SM, Lust JA, Allred JB, Witzig TE, Rajkumar SV, Greipp PR, Russell SJ, Kabat B, Gertz MA (2007) The activity of lenalidomide with or without dexamethasone in patients with primary systemic amyloidosis. Blood 109: 465-470.

11. Sanchorawala V, Wright DG, Rosenzweig M, Finn KT, Fennessey S, Zeldis JB, Skinner M, Seldin DC (2007) Lenalidomide and dexamethasone in the treatment of AL amyloidosis: results of a phase 2 trial. Blood 109: 492-496.

12. Richardson PG, Sonneveld P, Schuster MW, Irwin D, Stadtmauer EA, Facon T, Harousseau JL, Ben-Yehuda D, Lonial S, Goldschmidt H, Reece D, San-Miguel JF, Bladé J, Boccadoro M, Cavenagh J, Dalton WS, Boral AL, Esseltine DL, Porter JB, Schenkein D, Anderson KC; Assessment of Proteasome Inhibition for Extending Remissions (APEX) Investigators (2005) Bortezomib or high-dose dexamethasone for relapsed multiple myeloma. N Engl J Med 352: 2487-2498.

13. Gertz MA, Comenzo R, Falk RH, Fermand JP, Hazenberg BP, Hawkins PN, Merlini G, Moreau P, Ronco P, Sanchorawala V, Sezer O, Solomon A, Grateau G (2005) Definition of organ involvement and treatment response in immunoglobulin light chain amyloidosis (AL): a consensus opinion from the 10th International Symposium on Amyloid and Amyloidosis, Tours, France, 18-22 April 2004. Am J Hematol 79: 319-328.

14. Sitia R, Palladini G, Merlini G (2007) Bortezomib in the treatment of AL amyloidosis: targeted therapy? Haematologica 92: 1302-1307.

15. Teixeira PF, Cerca F, Santos SD, Saraiva MJ (2006) Endoplasmatic reticulum stress associated with extracellular aggregates. Evidence from transthyretin deposition in familial amyloid polyneuropathy. J Biol Chem 281: 21998-22003. 
16. Niesvizky R, Richardson PG, Rajkumar SV, Coleman M, Rosiñol L, Sonneveld P, Schuster MW, Irwin D, Stadtmauer EA, Facon T, Harousseau JL, Boral AL, Esseltine DL, Anderson KC, Bladé J (2008) The relationship between quality of response and clinical benefit for patients treated on the bortezomib arm of the international, randomized, phase 3 APEX trial in relapsed multiple myeloma. Br J Haematol 143: 46-53.

17. Harousseau JL, Palumbo A, Richardson PG, Schlag R, Dimopoulos MA, Shpilberg O, Kropff M, Kentos A, Cavo M, Golenkov A, Komarnicki M, Mateos MV, Esseltine DL, Cakana A, Liu K, Deraedt W, van de Velde H, San Miguel JF (2010) Superior outcomes associated with complete response in newly diagnosed multiple myeloma patients treated with non-intensive therapy: analysis of the phase 3 VISTA study of bortezomib plus melphalan-prednisone versus melphalan-prednisone. Blood, Jul 13. [Epub ahead of print].

18. Kastritis E, Wechalekar AD, Dimopoulos MA, Merlini G, Hawkins PN, Perfetti V, Gillmore JD, Palladini G (2010) Bortezomib with or without dexamethasone in primary systemic (light chain) amyloidosis. Journal of Clinical Oncology 28: 10311037. 


\section{Figures:}

Figure 1: Progression free survival for all patients:

Figure 1: Progression-free survival Kaplan-Meier Estimates

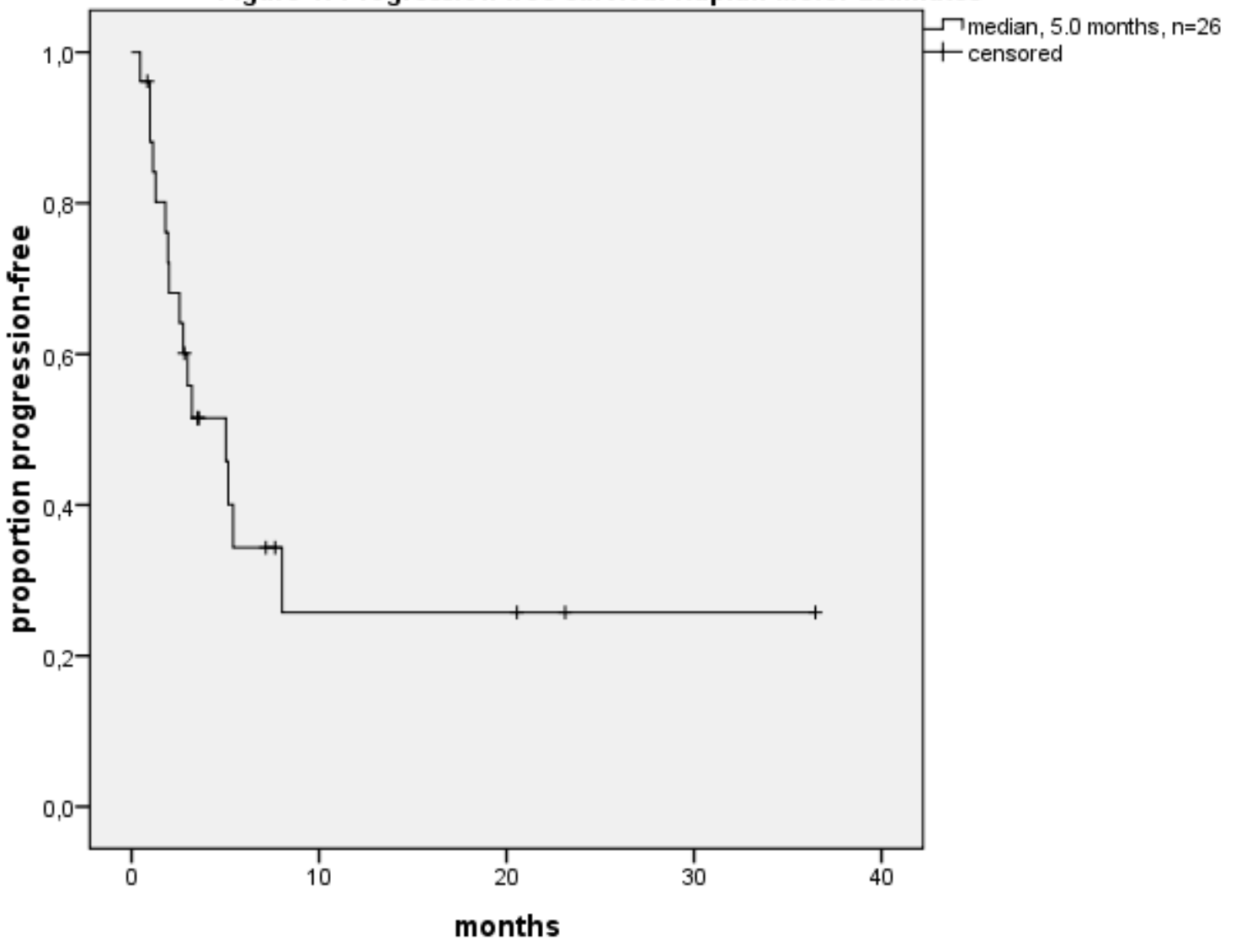


Figure 2: Progression free survival CR versus Non-CR:

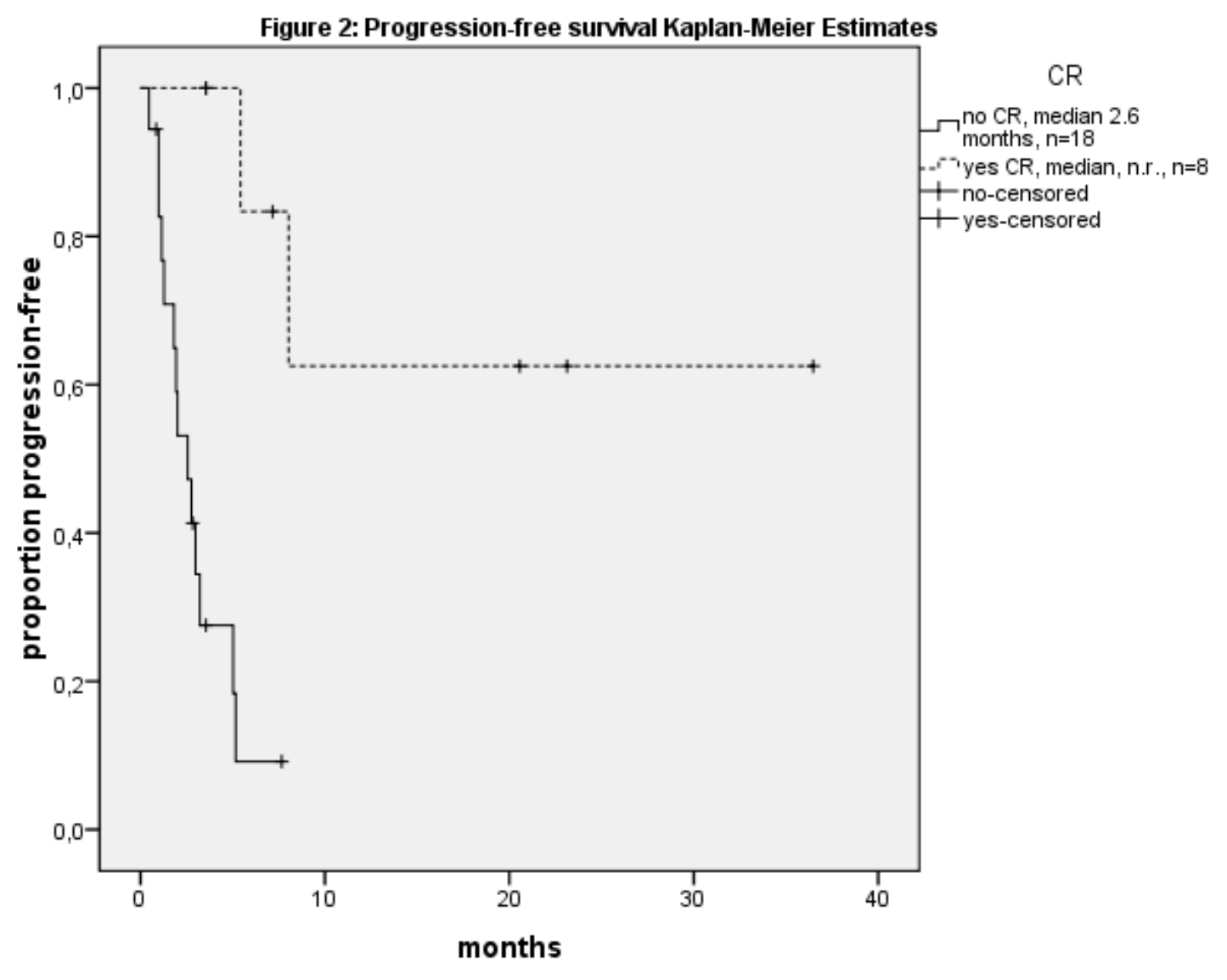


Figure 3: Overall survival for all patients:

Figure 3: Overall survival Kaplan-Meier Estimates

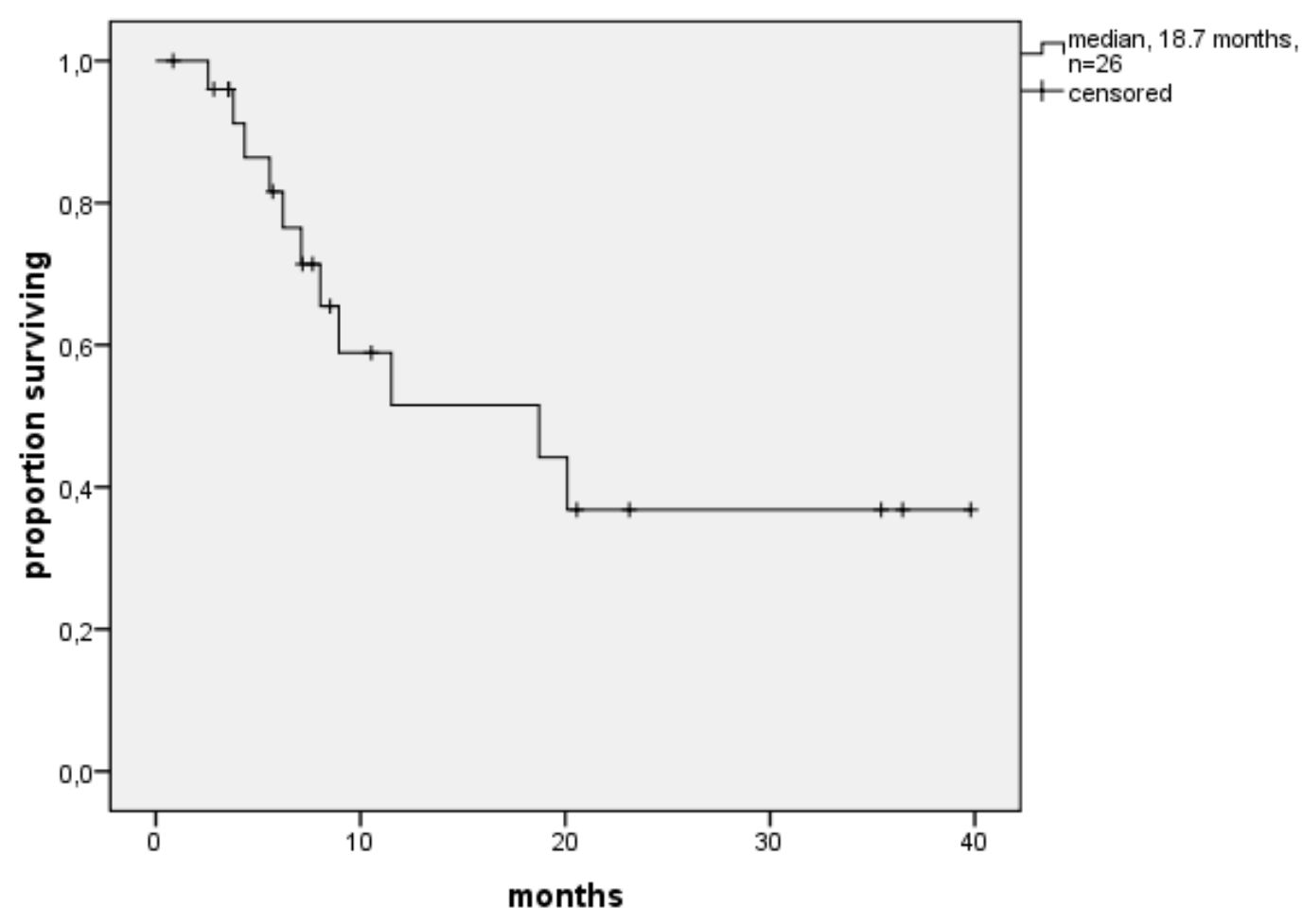


Figure 4: Overall survival CR versus Non-CR:

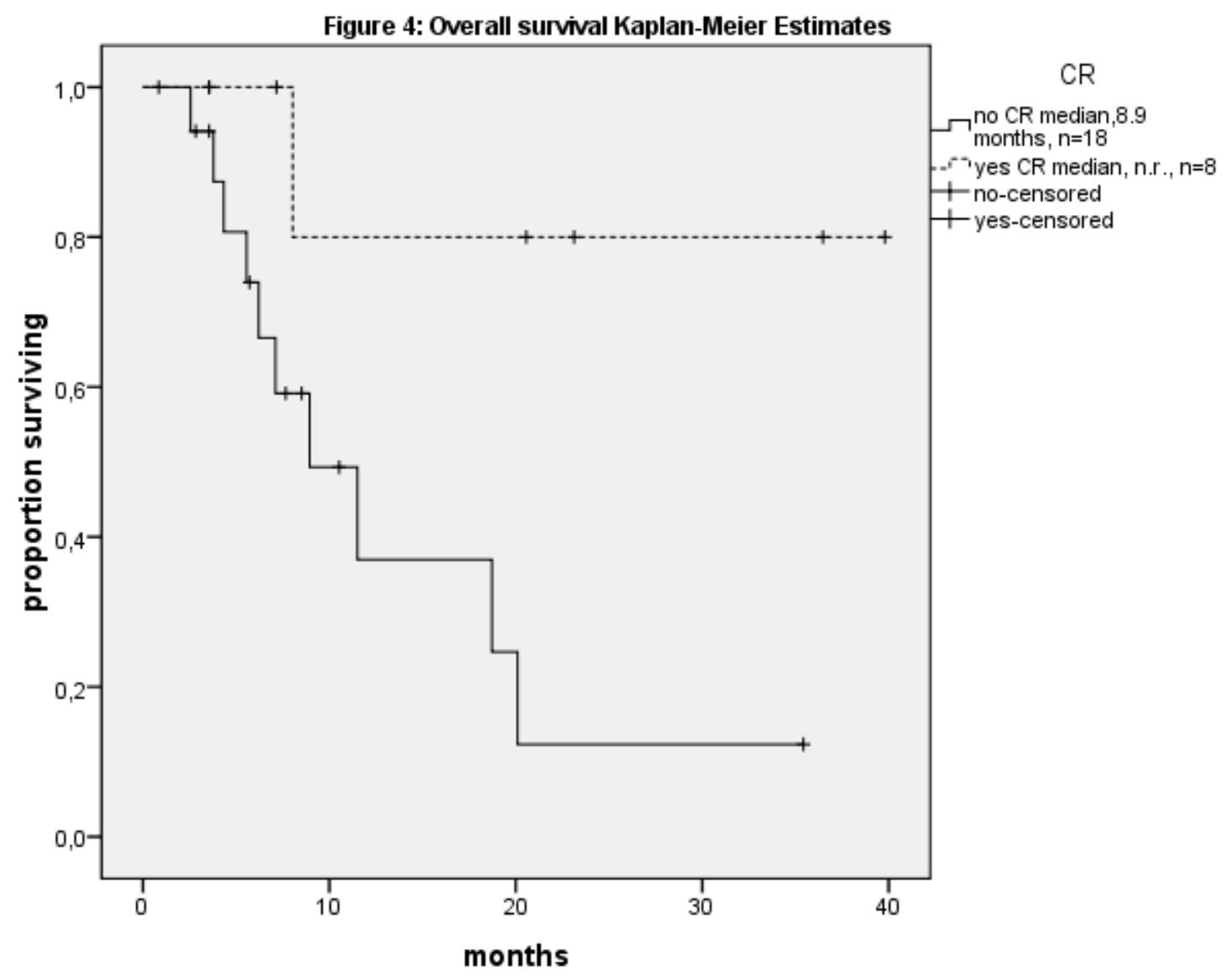




\begin{tabular}{|c|c|}
\hline $\begin{array}{l}\text { Table 1: Characteristics of } 26 \text { patients with AL: } \\
\text { Number of patients }\end{array}$ & Number (\%) \\
\hline \multicolumn{2}{|l|}{ Sex } \\
\hline - Male & $13(50 \%)$ \\
\hline - Female & $13(50 \%)$ \\
\hline \multicolumn{2}{|l|}{ Line in which Bortezomib is used: } \\
\hline - Median/range & $3(1-7)$ \\
\hline - Untreated & $18(69 \%)$ \\
\hline - Pretreated & $8(31 \%)$ \\
\hline - BD Cycles & Median 3 (range, 2 - 8) \\
\hline - Light chain type kappa/lambda & $7(27 \%) / 19(73 \%)$ \\
\hline - IgG/lgA/light chain only & $6(23 \%) / 2(8 \%) / 18(69 \%)$ \\
\hline - Bone marrow plasma cells (\%) & $7(0-70)$ \\
\hline \multicolumn{2}{|l|}{ Organ involvement } \\
\hline - Kidney & $26(100 \%)$ \\
\hline - Heart & $9(35 \%)$ \\
\hline - Liver & $4(15 \%)$ \\
\hline - Gastrointestinal tract & $3(12 \%)$ \\
\hline - Preripheral nerves & $2(8 \%)$ \\
\hline - Bone marrow & $2(8 \%)$ \\
\hline - Other & $2(8 \%)$ \\
\hline - Lymph nodes & $1(4 \%)$ \\
\hline \multicolumn{2}{|l|}{ Number of organs involved } \\
\hline-1 & $9(35 \%)$ \\
\hline-2 & $12(46 \%)$ \\
\hline$->2$ & $5(19 \%)$ \\
\hline \multicolumn{2}{|l|}{ Baseline biochemical measurements } \\
\hline$-\mathrm{BNP}>120 \mathrm{pg} / \mathrm{ml}$ & $9(35 \%)$ \\
\hline - beta 2 microglobulin $>3.5 \mathrm{mg} / \mathrm{l}$ & $11(42 \%)$ \\
\hline - Creatinine $>2 \mathrm{mg} / \mathrm{dl}$ & $3(12 \%)$ \\
\hline - Albumin $>3.5 \mathrm{~g} / \mathrm{dl}$ & $12(46 \%)$ \\
\hline - Proteinuria & $21(81 \%)$ \\
\hline Previous Treatment regimes: & $n=8$ \\
\hline$-\mathrm{MP}$ & $4(50 \%)$ \\
\hline$-V A D$ & $2(25 \%)$ \\
\hline - DCEP & $2(25 \%)$ \\
\hline - Other & $4(50 \%)$ \\
\hline
\end{tabular}




\begin{tabular}{|l|c|c|} 
& $\mathbf{N}=\mathbf{2 6}$ & $\mathbf{9 5 \%} \mathbf{~ C l}$ \\
\hline $\begin{array}{l}\text { Progression free survival } \\
\text { (median months) }\end{array}$ & 5.0 & $2.2-7.9$ \\
\hline $\begin{array}{l}\text { Overall survival } \\
\text { (median months) }\end{array}$ & 18.7 & \multicolumn{2}{|c|}{} \\
\hline Best response: & Hematologic (n/\%) & Organ (n/\%) \\
\hline- CR & $8(31 \%)$ & 0 \\
\hline - PR & $6(23 \%)$ & $3(12 \%)$ \\
\hline - SD & $11(42 \%)$ & $20(76 \%)$ \\
\hline- PD & $1(4 \%)$ & $3(12 \%)$ \\
\hline
\end{tabular}


Table 3: Major toxicities of treatment with B/D: 


\begin{tabular}{|l|c|c|} 
Toxicity & Grade 1+ 2 & Grade 3+4 \\
\hline Anemia & $70 \%$ & $0 \%$ \\
\hline Thrombopenia & $27 \%$ & $4 \%$ \\
\hline Leukopenia & $25 \%$ & $4 \%$ \\
\hline Akute renal failure & $4 \%$ & $0 \%$ \\
\hline Hyponatremia & $4 \%$ & $4 \%$ \\
\hline Hypokalemia & $4 \%$ & $0 \%$ \\
\hline Fatigue & $23 \%$ & $0 \%$ \\
\hline Diarrhea & $12 \%$ & $0 \%$ \\
\hline Constipation & $4 \%$ & $0 \%$ \\
\hline Nausea & $8 \%$ & $0 \%$ \\
\hline Edema & $27 \%$ & $0 \%$ \\
\hline Hypotension & $23 \%$ & $0 \%$ \\
\hline Arrhythmia & $4 \%$ & $4 \%$ \\
\hline Neurotoxicity & $42 \%$ & $0 \%$ \\
\hline Herpes zoster & $12 \%$ & $0 \%$ \\
\hline Other & $27 \%$ & $0 \%$ \\
\hline
\end{tabular}

